\title{
Schedule-dependent activity of 5-fluorouracil and irinotecan combination in the treatment of human colorectal cancer: in vitro evidence and a phase I dose-escalating clinical trial
}

\author{
C Barone*,', M Landriscina², M Quirino', M Basso', C Pozzo', G Schinzari', G Di Leonardo', E D’Argento', \\ N Trigila' and A Cassano' \\ 'Clinical Oncology Unit, Department of Internal Medicine, Catholic University, Rome, Italy; ${ }^{2}$ Clinical Oncology Unit, Department of Medical Sciences, \\ University of Foggia, Foggia, Italy
}

\begin{abstract}
Several schedules of 5-fluorouracil (FU) and irinotecan (IRI) have been shown to improve overall survival in advanced colorectal cancer (CRC). Preclinical evidence suggests that the sequential administration of IRI and FU produces synergistic activity, although their clinical use has not been fully optimised. We investigated the interaction between short-term exposure to SN-38, the active metabolite of IRI, and prolonged exposure to FU in human CRC HT-29 cells and observed that the synergism of action between the two agents can be increased by extending the time of cell exposure to FU and reducing the interval between administration of the two agents. Based on these findings, we performed a phase I trial in 25 advanced CRC patients using a modified IRI/FU regimen as first-line therapy and evaluated three dose levels of IRI $\left(150-300 \mathrm{mg} / \mathrm{m}^{2}\right)$ and two of continuous infusion of FU $\left(800-1000 \mathrm{mg} / \mathrm{m}^{2}\right)$ in a 3-weekly schedule. The most severe grade III-IV toxicities were neutropoenia in four cycles and diarrhoea in three. One patient achieved complete response (4\%), 12 a partial response (48\%), the overall response rate was 52\% ( $\pm 20,95 \% \mathrm{Cl}$ ); seven of 25 patients had stable disease (28\%), the overall disease control was $80 \%( \pm 16,95 \% \mathrm{Cl})$. This modified IRI/FU schedule is feasible and exhibits potentially interesting clinical activity.
\end{abstract}

British Journal of Cancer (2007) 96, 21 -28. doi:10.1038/sj.bjc.6603496 www.bjcancer.com

Published online 12 December 2006

(c) 2007 Cancer Research UK

Keywords: 5-fluorouracil; irinotecan; SN-38; colon carcinoma cells; phase I trial

Combination therapy with FU, IRI and oxaliplatin (1-OHP) administered in two- or three-drug regimens is the mainstay of treatment for advanced CRC (Venook, 2005; O’Neil and Goldberg, 2005). Indeed, regimens combining FU with IRI or l-OHP are equally effective in terms of response rate and overall survival (Tournigand et al, 2004) and represent the standard first-line treatment in advanced CRC (O'Neil and Goldberg, 2005). Although three combinations of IRI and FU (IFL, FOLFIRI and AIO + IRI) have been evaluated in phase III studies (Saltz et al, 2000; Douillard et al, 2000; Köhne et al, 2005), several other schedules have been proposed (Venook, 2005; Atalay et al, 2003). However, no randomised clinical trials have compared these different FU/IRI schedules, so that we do not know whether one regimen is better than others.

The most effective regimens combining FU and IRI were designed on the basis of preclinical evidence suggesting that the antiproliferative activity of the two agents is schedule-dependent (Guichard et al, 1997; Guichard et al, 1998; Mullany et al, 1998).

\footnotetext{
* Correspondence: Professor C Barone, U.O. Oncologia Medica, Università Cattolica del S. Cuore, Facoltà di Medicina e Chirurgia, Largo F. Vito, I -00I68 Roma, Italy; E-mail: carlobarone@rm.unicatt.it Received I5 August 2006; revised 26 October 2006; accepted 29 October 2006; published online 12 December 2006
}

Indeed, the administration of IRI before FU produced additive or synergistic effects in all colon carcinoma cell lines tested (Guichard et al, 1998; Mans et al, 1999), whereas both the exposure of cells to FU before IRI and the simultaneous administration of both drugs produced antagonistic or only additive activity, depending on the colon tumour cell model (Mans et al, 1999). Similar findings were also reported in vivo, in athymic mice xenografts of colon carcinoma cells (Guichard et al, 1997).

Several combination regimens with FU and IRI have been evaluated as first-line therapy for advanced CRC, achieving a response rate of $30-50 \%$ and an overall survival of 14-20 months (Venook, 2005; O'Neil and Goldberg, 2005). Interestingly, the most commonly used schedules - that is the FOLFIRI and IFL regimens - consist in the sequential administration of IRI followed by FU bolus and/or continuous infusion (c.i.). However, considering that the half-life of IRI is about $10 \mathrm{~h}$ (Robert and Rivory, 1998), both regimens also combine the two drugs simultaneously in a weekly (IFL regimen) or bi-weekly (FOLFIRI regimen) schedule (Douillard et al, 2000; Saltz et al, 2000). While there is no clinical evidence to prove that the drug interactions observed in preclinical models also occur in humans and may affect the effectiveness of FU- and IRI-based chemotherapy, the results obtained in vitro clearly indicate a schedule-dependency of the interaction between the two agents and suggest the possibility of improving the efficacy of the combination. We therefore looked more closely at the 
dependency of the synergism between FU and SN-38, the active metabolite of IRI, on the extent of cell exposure to FU and the interval between the two drugs in human colon carcinoma HT-29 cells and translated the findings obtained in vitro into clinical experience, evaluating a modified IRI/FU regimen in a phase I trial.

\section{PATIENTS AND METHODS}

Cell Cultures and Chemicals. HT-29 human colon carcinoma cells were cultured in DMEM containing $10 \%$ foetal bovine serum, glutamine and Penicillin/Streptomycin (Sigma-Aldrich, Italy) (Khatib et al, 2001). SN-38 was kindly provided by Aventis Inc., Paris, France. Stock solution of SN-38 was prepared in DMSO at $10 \mathrm{~mm}$. FU was purchased from Sigma-Aldrich and diluted in phosphate buffer saline. Either drugs or the same DMSO volume were added to the cultures at the concentrations specified in the Results; incubation was carried out continuously and fresh drugcontaining medium was changed at 24 -h intervals.

The cell-cycle phase distribution and the rate of necrosis and apoptosis were evaluated as previously reported (Landriscina et al, 2000; Sciamanna et al, 2005).

In order to select HT-29 colon carcinoma cells resistant to FU (HT29 FUR) or to SN-38 (HT29 SN-38R), cells were continuously incubated in the presence of increasing concentrations of FU and SN-38 starting from $0.1 \mathrm{~nm}$ for both drugs (Lesuffleur et al, 1991). Cells were finally stabilised in the presence of $9 \mu \mathrm{M} \mathrm{FU}$ and $100 \mathrm{nM}$ $\mathrm{SN}-38$. The resistance to each drug was assessed by MTT dye assay (see below) and by measuring apoptosis in the presence of increasing concentrations of FU or SN-38.

\section{Immunoblot analysis and cytotoxicity assay}

Immunoblot analysis was performed as previously reported (Landriscina et al, 2000). Specific bands were revealed using a mouse monoclonal anti-thymidylate synthase (TS) antibody (Histoline Laboratories, Italy).

Growth inhibition by cytotoxic agents was measured using the MTT (Sigma-Aldrich, Italy) dye assay as previously described (Zeghari-Squalli et al, 1999). Briefly, $10^{4}$ cells were seeded into 24 well plates and incubated, $24 \mathrm{~h}$ later, in the presence of increasing concentrations of FU $\left(10^{-4}-100 \mu \mathrm{M}\right)$ or SN-38 $\left(10^{-6}-10 \mu \mathrm{M}\right)$ as specified in the Results. Three independent cytotoxicity assays were used to calculate $\mathrm{EC}_{30} \mathrm{SN}-38$ and $\mathrm{EC}_{30} \mathrm{FU}$. Combination assays were performed using $\mathrm{EC}_{30} \mathrm{SN}-38(0.11 \mu \mathrm{M})$ or FU $(5.2 \mu \mathrm{M})$ with increasing concentrations of $\mathrm{FU}$ or $\mathrm{SN}-38$, respectively. $\mathrm{SN}-38$ was always administered for $6 \mathrm{~h}$, whereas $\mathrm{FU}$ was administered for $24-96 \mathrm{~h}$, as specified in the Results. In the sequential schedule, the second drug was administered immediately after the first drug or, in some experiments, after an incubation of cells in a drug-free medium for $24-96 \mathrm{~h}$. After the removal of both drugs, cells were incubated in a drug-free medium for $72 \mathrm{~h}$ and $50 \mu \mathrm{l}$ of a $125 \mu \mathrm{M}$ MTT solution were then added to each well. The plates were incubated for additional $3 \mathrm{~h}$ at $37^{\circ} \mathrm{C}$ to allow MTT metabolism into formazan crystals. The formazan crystals were finally solubilised by adding $200 \mu \mathrm{l}$ of $0.04 \mathrm{~N} \mathrm{HCl}$ in isopropanol to each microplate well. Adsorbance at $540 \mathrm{~nm}$ was measured using a Bio-Tek microplate reader (model EL-340; BioMetallics, Priceston, NJ, USA). Wells containing only DMEM, $10 \%$ FBS and MTT were used as controls. Each experiment was performed at least three times, using four replicates for each drug concentration.

\section{Analysis of combination effects}

Combination analysis was performed using the method described by Chou et al. (Chou and Talalay, 1984; Chou et al, 1994). The influence of the two drugs on the combination was evaluated by comparing the sequential assay with assays involving the two drugs simultaneously or alone. The combination effect was evaluated from isoeffect analysis CIs, calculated as follows:

$$
\mathrm{CI}=\mathrm{C}_{\mathrm{FU}} / \mathrm{Cx}_{\mathrm{FU}}+\mathrm{C}_{\mathrm{SN}-38} / \mathrm{Cx}_{\mathrm{SN}-38}
$$

where $\mathrm{Cx}_{\mathrm{FU}}$ and $\mathrm{Cx}_{\mathrm{SN}-38}$ are respectively the concentrations of $\mathrm{FU}$ and $\mathrm{SN}-38$ alone needed to achieve a given effect $(x \%)$ and $\mathrm{C}_{\mathrm{FU}}$ and $\mathrm{C}_{\mathrm{SN}-38}$ are the concentrations of the two drugs needed to obtain the same effect when FU and SN-38 are combined. The CIs were calculated under the assumption of a mutually exclusive drug interaction. The combination was considered as positive (synergistic) when the combination index was $<1$ and negative (antagonistic) when it was $>1$.

\section{Patients}

Patients with locally advanced or metastatic CRC, histologically or cytologically proven, were eligible for this study. Minimum age for enrolment was 18 years. Other requisites of eligibility were disease measurability according to RECIST criteria (Therasse et al, 2000); PS (ECOG) 0-2; adequate organ function: white blood cell count $>3000 / \mu \mathrm{l}$, platelet count $>100000 / \mu \mathrm{l}, \mathrm{Hgb}>12 \mathrm{~g} / \mathrm{dl}$, creatinine $<1.5 \mathrm{mg} / \mathrm{dl}$, total bilirubin $<2 \mathrm{mg} / \mathrm{dl}$ and transaminase levels $<3$ times upper normal limits. FU- and folinic acid (LFA)-based adjuvant chemotherapy and prior surgery for primary tumour were allowed. All patients were informed of the investigational nature of the study and expressed written informed consent. The study was approved by the local Ethics Committee.

\section{Clinical study design}

To translate the results of the preclinical part of this study, an open-label, dose-escalating phase I trial was designed in which groups of four to six patients were to receive increasing doses of IRI and c.i. FU until dose-limiting toxicity (DLT) was demonstrated in at least two of six patients. Four dose levels of IRI and two of FU were evaluated in this study. We obtained five cohorts of patients: (i) IRI $150 \mathrm{mg} / \mathrm{m}^{2}$ and FU $800 \mathrm{mg} / \mathrm{m}^{2}$ as a 4 -day c.i., (ii) IRI $200 \mathrm{mg} / \mathrm{m}^{2}$ and $\mathrm{FU} 800 \mathrm{mg} / \mathrm{m}^{2}$ as a 4 -day c.i., (iii) IRI $250 \mathrm{mg} / \mathrm{m}^{2}$ and FU $800 \mathrm{mg} / \mathrm{m}^{2}$ as a 4 -day c.i., (iv) IRI $250 \mathrm{mg} / \mathrm{m}^{2}$ and FU $1000 \mathrm{mg} / \mathrm{m}^{2}$ as a 5-day c.i. and (v) IRI $300 \mathrm{mg} / \mathrm{m}^{2}$ and FU $1000 \mathrm{mg} / \mathrm{m}^{2}$ as a 5-day c.i. IRI was administered intravenously as $1 \mathrm{~h}$ infusion, while FU was given starting $24 \mathrm{~h}$ after IRI administration by means of portable infusion pumps in an outpatient setting. Cycles were repeated every 3 weeks until the maximum number of 12 was reached.

Toxicity was evaluated according to NCI-CTC version 2. DLT was defined as the occurrence of grade III nonhaematological toxicity, except alopecia, asthaenia, nausea and vomiting, or grade IV neutropoenia complicated by fever or lasting for more than 5 days, or grade IV thrombocytopoenia, or a delay of more than 2 weeks in treatment due to toxicity. A minimum of four patients was observed for at least one complete cycle of combination therapy before escalating to the next dose level. In the event that fewer than two patients experienced DLT at the same dose level, a minimum of four patients were entered at the next higher dose level. All patients in the prior cohort were required to have completed one cycle of therapy before enrolment in the next cohort began. If two instances of DLT were observed at any dose level, the maximum tolerated dose (MTD) was considered to have been exceeded and a total of six patients were to be treated at the previous dose level to confirm its tolerability.

Response was evaluated after four cycles according to RECIST criteria and confirmed within 6 weeks. Patients received up to 12 cycles of chemotherapy provided they had stable disease, partial or complete response. Treatment was interrupted in the event of 
unacceptable toxicity, disease progression, patient refusal or physician's decision.

\section{RESULTS}

The synergism between $\mathrm{SN}-38$ and $\mathrm{FU}$ in vitro depends on the extent of cell exposure to FU and the interval between administration of the two drugs

In preliminary experiments, we confirmed in human colon carcinoma HT-29 cells the well known evidence that the synergism between FU and SN-38 is schedule-dependent, with maximal supra-additive effect when SN-38 is administered first (Guichard et al, 1997; Guichard et al, 1998; Mullany et al, 1998). Cells were therefore exposed to (i) SN-38 alone for $6 \mathrm{~h}, \mathrm{FU}$ alone for $24 \mathrm{~h}$, (ii) the simultaneous combination of the two drugs (SN-38 and FU for $6 \mathrm{~h}$ followed by FU for $18 \mathrm{~h}$ ) or (iii) both sequential combinations of the two drugs (SN-38 for $6 \mathrm{~h}$ and $\mathrm{FU}$ for $24 \mathrm{~h}$ and vice versa). The CI isobologram equation was used for the analysis of the interaction between SN-38 and FU (Chou and Talalay, 1984; Chou et al, 1994).

Figure 1A illustrates the results obtained after exposure of HT29 cells (i) to increasing concentrations of FU alone $\left(10^{-4}-100 \mu \mathrm{M}\right)$ or (ii) to the combination of $\mathrm{EC}_{30} \mathrm{SN}-38(0.11 \mu \mathrm{M})$ and increasing concentrations of $\mathrm{FU}$ using both sequences or after concomitant exposure to $\mathrm{EC}_{30} \mathrm{SN}-38$ and increasing concentrations of $\mathrm{FU}$.
A

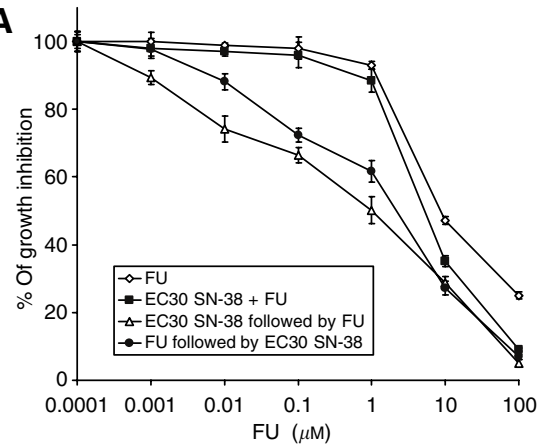

B
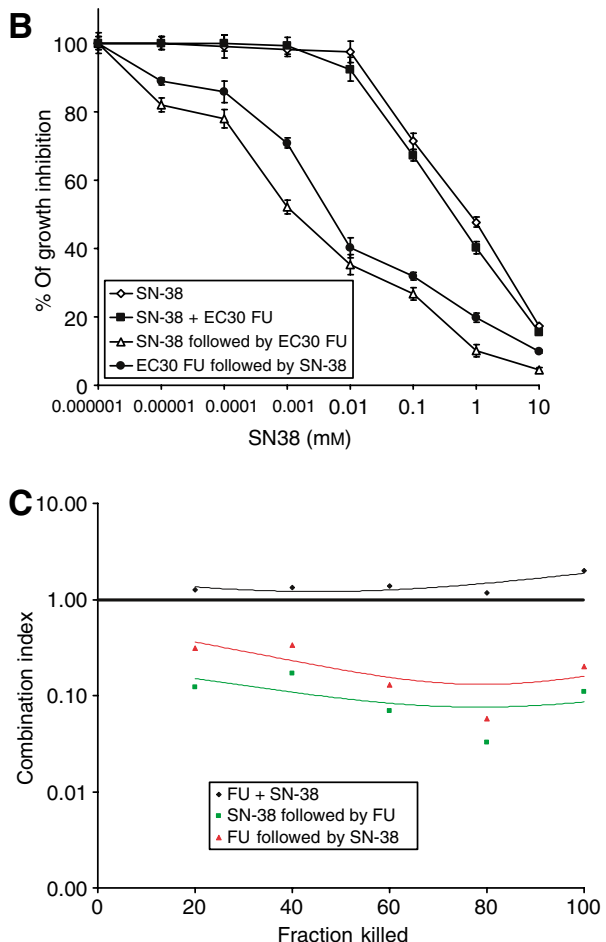
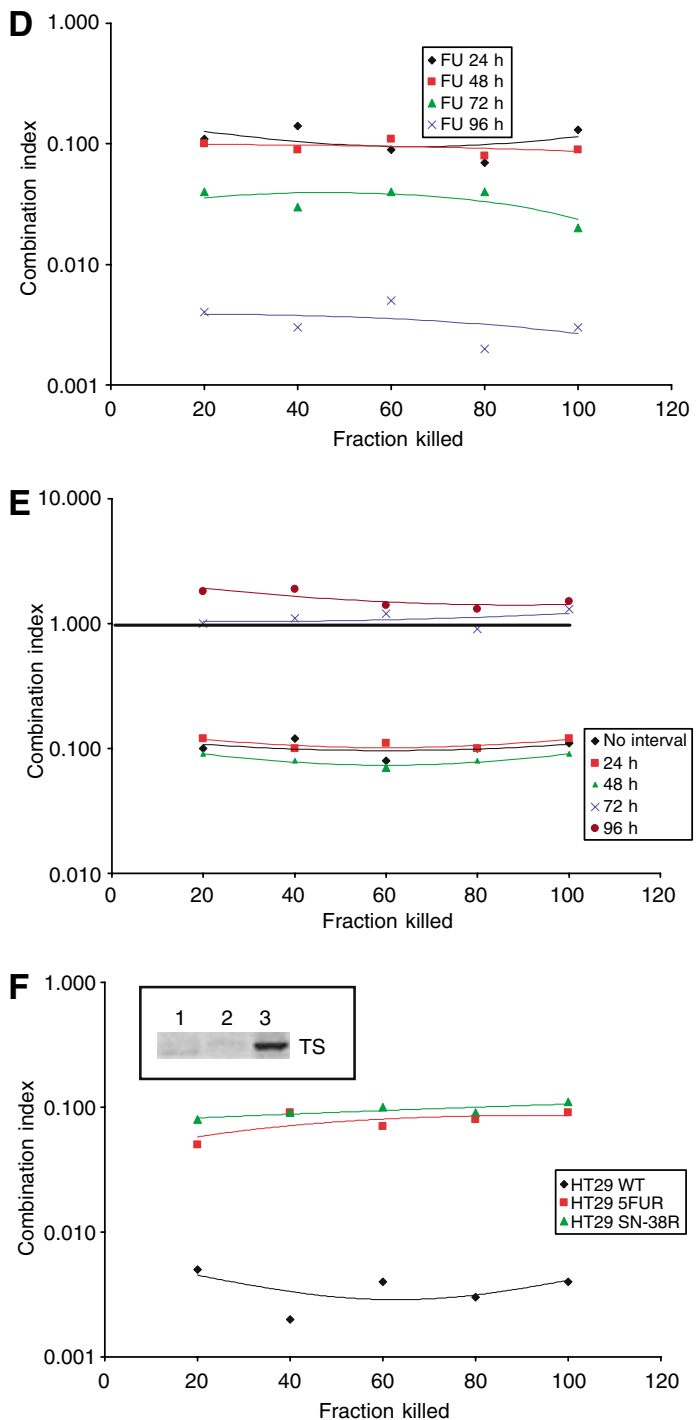

Figure I The schedule-dependent synergism between SN-38 and FU. (A) Cytotoxicity evaluated by MTT assay after exposure of human colon carcinoma HT-29 cells to increasing concentrations of FU $\left(10^{-4}-100 \mu \mathrm{M}\right)$ for $24 \mathrm{~h}$, the sequential combination of $\mathrm{EC}_{30} \mathrm{SN}-38(0.1 \mathrm{l} \mu \mathrm{M})$ for $6 \mathrm{~h}$ and increasing concentrations of FU for $24 \mathrm{~h}$ using both sequences and the concomitant treatment with $\mathrm{EC}_{30} \mathrm{SN}-38$ for $6 \mathrm{~h}$ and increasing concentrations of FU for $24 \mathrm{~h}$. (B) Cytotoxicity evaluated by MTT assay after exposure of HT-29 to increasing concentrations of SN-38 $\left(10^{-6}-10 \mu \mathrm{M}\right)$ for $6 \mathrm{~h}$, the sequential combination of $\mathrm{EC}_{30} \mathrm{FU}(5.2 \mu \mathrm{M})$ for $24 \mathrm{~h}$ and increasing concentrations of SN-38 for $6 \mathrm{~h}$ using both sequences and the concomitant treatment with $\mathrm{EC}_{30} \mathrm{FU}$ for $24 \mathrm{~h}$ and increasing concentrations of SN-38 for $6 \mathrm{~h}$. (C) Plot of the Cls vs the cytotoxicity, calculated from data reported in $(\mathbf{A}, \mathbf{B})$, using the methods described by Chou et al (20-2I) and under the assumption of a mutually exclusive drug interaction. $\mathrm{Cl}>\mathrm{I}$, antagonism; $\mathrm{Cl}=\mathrm{I}$, additive effect; $\mathrm{Cl}<\mathrm{I}$, synergism. (D) Plot of the Cls vs the cytotoxicity calculated from MTT assay data of HT-29 cells exposed sequentially to SN-38 for $6 \mathrm{~h}$ followed by FU for 24 , 48, 72 and $96 \mathrm{~h}$. (E) Plot of the Cls vs the cytotoxicity calculated from MTT assay data of HT-29 cells exposed to SN-38 for $6 \mathrm{~h}$ followed by FU for $24 \mathrm{~h}$ after an interval between the two drugs of $0,24,48,72$ and $96 \mathrm{~h}$ during which cells were incubated in a drug-free medium. (F) Plot of the Cls vs the cytotoxicity obtained from MTT assay data of HT-29, HT-29 SN-38R and HT-29 FUR cells exposed to the sequence of SN-38 followed by FU for $96 \mathrm{~h}$. Insert: Thymidylate synthase (TS) protein expression in wild-type HT-29 (line I), HT-29 SN-38R (line 2) and HT-29 FUR (line 3) cells. 
Figure 1B shows HT-29 cells grown in the presence of increasing concentrations of SN-38 alone $\left(10^{-6}-10 \mu \mathrm{M}\right), \mathrm{EC}_{30} \mathrm{FU}(5.2 \mu \mathrm{M})$ and increasing concentrations of $\mathrm{SN}-38$ in both sequences or concomitantly with $\mathrm{EC}_{30} \mathrm{FU}$ and increasing concentrations of SN38. As reported in Figure 1C, the maximal synergism between FU and $\mathrm{SN}-38$ was achieved when $\mathrm{SN}-38$ was administered before FU (green line). However, a synergism of action was also observed with the reverse sequence (red line), whereas only an additive effect was found with the concomitant exposure of HT-29 cells to both drugs (black line).

As in clinical experience IRI is always administered as a short infusion, while $\mathrm{FU}$ is administered either by bolus or as c.i. (Venook, 2005; O'Neil and Goldberg, 2005), we designed specific experiments to evaluate the possibility of improving the synergism between $\mathrm{SN}-38$ and FU by prolonging the extent of cell exposure to FU. We therefore evaluated the synergism between a brief exposure $(6 \mathrm{~h})$ to $\mathrm{SN}-38$ followed by a longer exposure to FU (24$96 \mathrm{~h})$. As reported in Figure 1D, the synergism between the two drugs was increased by prolonging the exposure of cells to FU, reaching the maximal activity when cells were exposed to FU for $96 \mathrm{~h}$ (blue line).

In a third set of experiments (Figure 1E), HT-29 cells were exposed to the sequence of SN-38 for $6 \mathrm{~h}$ followed by FU for $24 \mathrm{~h}$, but the second drug was added to the cell culture immediately after (black line) or after an interval of 24 (red line), 48 (green line), 72 (blue line) or $96 \mathrm{~h}$ (brown line) during which cells were incubated in a drug-free medium. Interestingly, the synergism between SN-38 and FU was unchanged whether the drug-free interval between $\mathrm{SN}$ 38 and FU was 24 or $48 \mathrm{~h}$. In contrast, when cells were exposed to the sequence of SN-38 and FU with a drug-free interval of 72 or $96 \mathrm{~h}$ in between, the combination of the two cytotoxic agents obtained only additive effects.

The sequential combination of $\mathrm{SN}-38$ and $\mathrm{FU}$ results in an increase in apoptosis and S-phase of the cell cycle

HT-29 cells were treated with the two drugs alone or with the combination of $\mathrm{SN}-38$ and $\mathrm{FU}$ and evaluated for the rate of apoptosis and necrosis and the cell cycle distribution. Cells treated with increasing concentrations of SN-38 $(0.001-1 \mu \mathrm{M})$ and FU $(0.1-100 \mu \mathrm{M})$ revealed a dose-dependent increase in apoptosis which is maximal at $100 \mathrm{nM} \mathrm{SN}-38$ and $10 \mu \mathrm{M}$ FU (data not shown). Cells were exposed to $10 \mathrm{~nm} \mathrm{SN-38}$ or $1 \mu \mathrm{M}$ FU for $24 \mathrm{~h}$, the combination of both drugs for $24 \mathrm{~h}$ or sequentially exposed to both drugs for $24 \mathrm{~h}$. The sequential exposure of cells to SN-38 before FU elicited the maximal increase in apoptosis, while the reverse sequence produced intermediate levels of apoptosis compared with the simultaneous exposure (Table 1). Interestingly, when the cells were sequentially exposed to the two agents with an incubation of $96 \mathrm{~h}$ in a drug-free medium after $\mathrm{SN}-38$, the rate of apoptosis was significantly lower and was comparable to that observed with the simultaneous exposure (Table 1).

The cell cycle distribution in HT-29 cells exposed to (i) $1 \mu \mathrm{M}$ FU for $24 \mathrm{~h}$, (ii) $10 \mathrm{~nm} \mathrm{SN}-38$ for $24 \mathrm{~h}$, (iii) the combination of both drugs for $24 \mathrm{~h}$ and (iv) the sequence of both drugs for $24 \mathrm{~h}$ was further evaluated. FU produced an arrest of cells in S-phase of the cell cycle, whereas SN-38 produced an arrest in the G2-M phase (Table 2). Interestingly, HT-29 colon carcinoma cells sequentially exposed to SN-38 followed by FU exhibited a significantly higher increase in the S-phase fraction with no arrest in the G2-M phase, while HT-29 cells exposed sequentially to FU followed by SN-38 exhibited an arrest of the cell cycle in both S- and G2-M phases with a magnitude similar to that produced by the single agents. In contrast, cells simultaneously exposed to SN-38 and FU exhibited an arrest of the cell cycle in the S-phase similar to that induced by FU alone, but not in the G2-M phase (Table 2).

\section{The synergism between $\mathrm{SN}-38$ and $\mathrm{FU}$ is partially conserved in colon carcinoma HT-29 cells resistant to FU or $\mathrm{SN}-38$}

In order to evaluate whether the synergism between SN-38 and FU is able to overcome resistance to the individual agents, we obtained HT-29 cells resistant to SN-38 (HT-29 SN-38R) or FU (HT-29 FUR) and evaluated the interaction between the two drugs in both cell lines. HT-29 SN-38R and HT-29 FUR cells required concentrations of SN-38 or FU about 10 times higher than wild-type HT-29 cells to exhibit similar rates of cytotoxicity or apoptosis (data not shown). Moreover, HT-29 FUR cells exhibited increased protein levels of TS (Figure1D, inset), the molecular target of FU (van Triest et al, 1999), which is in agreement with the well known observation that the upregulation of TS is responsible for resistance to FU (Wong et al, 2001). The cytotoxicity of the sequence of SN-38 followed by FU for $96 \mathrm{~h}$ was evaluated in HT-29, HT-29 SN-38R and HT-29 FUR cells. In single agent-resistant cells the synergism between SN-38 and FU was still observed, albeit with a magnitude lower than that obtained in wild-type HT29 cells (Figure 1F).

\section{Patient population, toxicity and clinical activity}

Between January 2003 and December 200425 patients were enrolled in the clinical study. Patients' characteristics are listed in Table 3, while toxicities are reported in Table 4. A total of 203 cycles was administered without observing treatment-related deaths. We reported three DLTs, all of which were grade III diarrhoea, in separate patients. The first patient at step 3 resumed treatment at a dose of $75 \%$ after recovering from grade II nausea/ vomiting, while grade III diarrhoea occurred during the first cycle and was not repeated after dose reduction. The second and the third patients experienced grade III diarrhoea at the second and fourth cycle, respectively, and resumed treatment at full doses with no further grade III toxicities. As we did not observe a minimum of two DLTs at the same dose level, the MTD was not reached. Grade

Table 2 Cell cycle distribution of human colon carcinoma HT-29 cells exposed to different combinations of SN-38 and FU

\begin{tabular}{|c|c|c|c|}
\hline & G0-GI & $\mathbf{S}$ & G2-M \\
\hline Control & $62.8 \pm 0.8$ & $27.0 \pm 0.9$ & $10.2 \pm 1.0$ \\
\hline $10 \mathrm{~nm}$ SN-38 & $42.8 \pm 1.1$ & $31.5 \pm 1.4$ & $25.7 \pm 0.9$ \\
\hline $\mathrm{I} \mu \mathrm{MFU}$ & $45.9 \pm 1.4$ & $44.1 \pm 1.6$ & $10.0 \pm 0.7$ \\
\hline $10 \mathrm{nM} \mathrm{SN}-38+1 \mu \mathrm{M} F U$ & $40.9 \pm 1.6$ & $46.0 \pm 0.7$ & $13.1 \pm 1.3$ \\
\hline $10 \mathrm{nM}$ SN-38 $\rightarrow \mathrm{I} \mu \mathrm{M} \mathrm{FU}$ & $37.2 \pm 1.4$ & $60.8 \pm 1.9$ & $2.0 \pm 0.2$ \\
\hline $\mathrm{I} \mu \mathrm{M} \mathrm{FU} \rightarrow 10 \mathrm{nM} \mathrm{SN}-38$ & $34.5 \pm 1.1$ & $45.4 \pm 2.3$ & $20.1 \pm 1.2$ \\
\hline
\end{tabular}

Table I Analysis of cell viability in human colon carcinoma HT-29 cells exposed to different combinations of SN-38 and FU

\begin{tabular}{lrrrrrrr}
\hline & Control & I0 nM SN-38 & $\mathbf{I} \boldsymbol{\mu \mathbf { M }} \mathbf{~ F U}$ & $\mathbf{S N - 3 8 + F U}$ & $\mathbf{S N - 3 8} \rightarrow \mathbf{F U}$ & $\mathbf{F U} \rightarrow \mathbf{S N - 3 8}$ & $\mathbf{S N - 3 8} \rightarrow \mathbf{9 6} \mathbf{h} \rightarrow \mathbf{F U}$ \\
\hline Viable cells & $92.0 \pm 1.7$ & $87.3 \pm 1.3$ & $84.6 \pm 1.9$ & $71.7 \pm 1.3$ & $59.7 \pm 1.9$ & $66.3 \pm 2.3$ & $74.6 \pm 1.7$ \\
Apoptosis & $6.8 \pm 0.8$ & $11.9 \pm 0.7$ & $13.1 \pm 0.5$ & $26.5 \pm 0.9$ & $38.9 \pm 0.5$ & $31.9 \pm 0.7$ & $23.9 \pm 1.5$ \\
Necrosis & $1.2 \pm 0.1$ & $0.8 \pm 0.4$ & $2.3 \pm 0.3$ & $1.8 \pm 1.1$ & $1.4 \pm 0.3$ & $1.8 \pm 0.5$ & $1.5 \pm 0.7$ \\
\hline
\end{tabular}


III neutropoenia was recorded in four patients and was managed with G-CSF administration. Mucositis and gastrointestinal toxicity (i.e. diarrhoea and nausea/vomiting) were the most relevant and frequently observed grade I/II toxicities; they were generally mild

Table 3 Baseline characteristics of the patients

\begin{tabular}{|c|c|c|c|}
\hline Patients & & 25 & \\
\hline \multicolumn{4}{|l|}{ Age } \\
\hline Range & & $35-79$ & \\
\hline Median & & 60 & \\
\hline \multicolumn{4}{|l|}{ Sex } \\
\hline Female & & 7 & \\
\hline Male & & 18 & \\
\hline PS ECOG & $\mathrm{N}$ & & $\%$ \\
\hline 0 & 19 & & 76 \\
\hline 1 & 5 & & 20 \\
\hline 2 & I & & 4 \\
\hline
\end{tabular}

Previous surgery

Resection/colectomy $\quad 18$

Bypass

None

Adjuvant CT

Metastatic site

Liver

Lung

Nodes

Peritoneum

Other and rapidly reversible. The treatment was never interrupted due to toxicity.

Efficacy data are summarised in Table 5. The most remarkable result is 1 complete response, which lasted over 10 months. Twelve patients achieved a partial response (48\%). Stable disease was observed in seven patients $(28 \%)$, while progressive disease was recorded in five patients (20\%). Overall response and disease control rates were $52 \%( \pm 20,95 \% \mathrm{CI})$ and $80 \%( \pm 16,95 \% \mathrm{CI})$, respectively. Median time to progression was 7 months (range 2-11 months).

Three patients who had received adjuvant chemotherapy were enrolled in this trial. The first had relapsed 2 months after the end of adjuvant treatment, while the other two relapsed after 24 and 48 months, respectively. The first two patients were enrolled at step 3 and the third at step 5 and, interestingly, all of them achieved a partial response. The first two patients recorded a time to further progression of 9 months, while the third, who also

Table 5 Overall and partial response rates in patients who received different dose levels of the combination of FU and IRI

\begin{tabular}{lccrr}
\hline & CR & PR & S & PD \\
\hline Step 1 & 0 & 0 & 2 & 2 \\
Step 2 & 0 & 2 & 1 & 1 \\
Step 3 & 0 & 4 & 0 & 1 \\
Step 4 & 0 & 3 & 3 & 0 \\
Step 5 & 1 & 3 & 1 & 1 \\
Total & 1 & 12 & 7 & 5 \\
\% & 4 & 48 & 28 & 20 \\
Response rate (\%) & & 52 & & \\
Disease control rate (\%) & & 80 & & \\
\hline
\end{tabular}

Table 4 Adverse events in patients who received different dose levels of the combination of FU and IRI

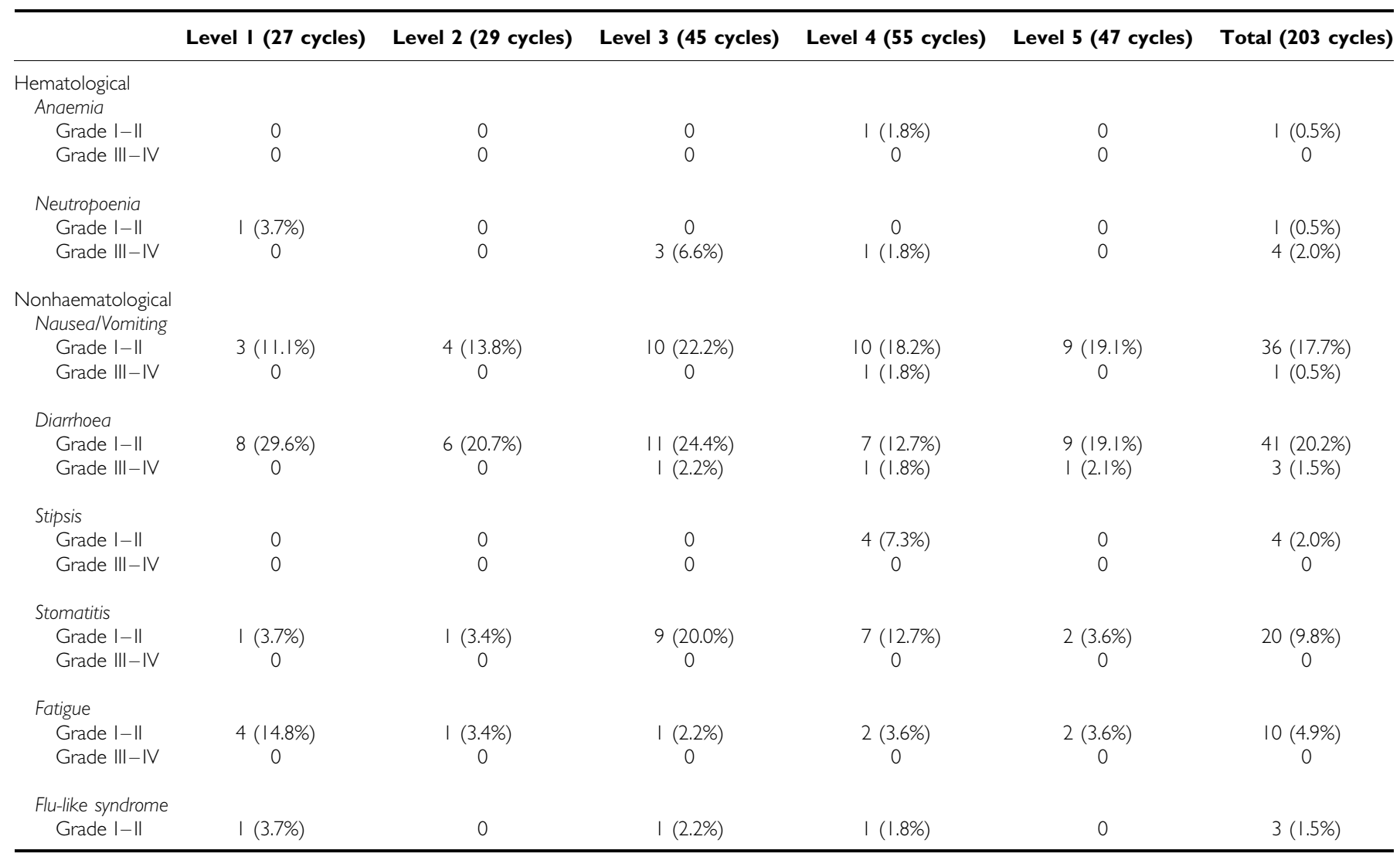


received radiation therapy on a iuxta-vertebral lymph-node metastasis, was progression-free at the time of this statistical analysis (11 months after the end of chemotherapy).

Most patients had a good PS at the end of treatment and all of them received second-line treatment.

\section{DISCUSSION}

Over the past 10 years the treatment of advanced CRC has progressed dramatically, with a shift from monotherapy to combination therapy and, more recently, to sequential combination therapy (Venook, 2005; O'Neil and Goldberg, 2005; Kelly and Goldberg, 2005). The introduction of IRI and l-OHP in the firstand second-line setting has increased the complexity of delivery of care to patients. Moreover, the recent development of moleculartargeted agents that are tumour-specific and have different toxicity profiles from chemotherapeutic agents has further widened the range of therapies for this disease (Venook, 2005; O'Neil and Goldberg, 2005). As these more efficacious agents allow patients to survive longer and to receive more lines of therapy, issues have arisen concerning the choice of the best schedule and the best sequence of treatments. However, while most of the regimens combining l-OHP and FU differ only marginally, the combinations of IRI and FU are characterised by major differences in terms of doses and schedules (Venook, 2005; O'Neil and Goldberg, 2005; Tournigand et al, 2004; Saltz et al, 2000; Douillard et al, 2000).

In the present study we investigated, at preclinical level, the interaction between FU and SN-38, the active metabolite of IRI, in order to obtain in vitro evidence for optimising chemotherapeutic schedules. We observed that (i) the sequential exposure of colon carcinoma cells to the two agents produces a supra-additive effect with maximal cytotoxic activity when cells are pre-exposed to $\mathrm{SN}$ 38 before FU, (ii) this synergism of action is partially conserved in colon carcinoma cells resistant to $\mathrm{SN}-38$ or FU, and, interestingly, (iii) it is possible to strengthen this synergism of action further by prolonging the exposure of tumour cells to $\mathrm{FU}$ and by administering the two agents sequentially with minimal interval in between.

Other preclinical studies previously suggested that preincubation of colon carcinoma cells with IRI before FU enhances the incorporation of FU derivatives into the DNA and DNA - protein complexes with a parallel and more persistent decrease in TS activity (Guichard et al, 1998). Furthermore, increased DNA damage was also observed in SW620 and HT-29 colon carcinoma cells when cells were pre-exposed to IRI before FU (Mans et al, 1999). These results are in agreement with our findings that the sequential exposure of colon carcinoma cells to SN-38 before FU produces a significant increase either in apoptosis or in the Sphase arrest. Indeed, while FU produced an arrest of cells in Sphase of the cell cycle and SN-38 produced an arrest in the phase G2-M, as previously reported (Mullany et al, 1998; Yoshikawa et al, 2001; McDonald and Brown, 1998), tumour cells sequentially exposed to $\mathrm{SN}-38$ followed by FU exhibited a significantly higher increase in the S-phase fraction with no arrest in the G2-M phase. Thus, it is likely that preincubation of colon carcinoma cells with SN-38 facilitates in turn a more prolonged inhibition of TS by FU, an increase in the incorporation of FU derivatives into DNA, an enhanced and persistent S-phase arrest and apoptotic cell death. This hypothetical mechanism of action provides a molecular rationale to our results showing that the synergistic activity of the $\mathrm{SN}-38$ and FU sequence is partially conserved in colon carcinoma cells resistant to FU and characterised by increased levels of TS. It is also in agreement with the clinical observation that the FU- and IRI-based combination therapy is effective in patients pretreated with FU (Andre et al, 1999) and whose tumours are generally characterised by increased levels of TS (Wong et al, 2001) as well as with our results obtained in three patients previously treated with FU-based adjuvant chemotherapy who achieved partial response with this modified FU/IRI regimen. Furthermore, our results suggest that IRI-resistant CRC cells may be more sensitive to schedules with c.i. FU, although the molecular mechanism of this synergism is still unclear.

The evidence that pre-incubation of HT-29 colon carcinoma cells with FU before SN-38 achieves synergism of action is partially in contrast with results reported by other authors, which suggest that the sequential exposure of cells to FU before IRI produces only additive activity (Mans et al, 1999). These differences may depend on the specific colon tumour cell model used.

Based on these preclinical findings and considering the low toxicity profile of infusional FU (Poplin et al, 2005), we designed a modified IRI/FU schedule with IRI administered on day 1 followed by a 4- or 5-day infusion of FU. We tested this alternative FU/IRIbased regimen in a phase I trial, evaluating three dose levels of IRI and two of FU in a 3-weekly schedule. Compared with the commonly used two-drug regimens (Venook, 2005), our schedule proved feasible and did not increase either haematological toxicity or the rate of high-grade diarrhoea and stomatitis. This is even more relevant in view of the toxicity profile of some traditional combination regimens of IRI and FU (i.e. IFL) in which a large proportion of patients experienced grade III-IV haematological and nonhaematological toxicity (Saltz et al, 2000). Although the MTD was not reached it is unlikely that this depends on the dose levels of IRI and FU. Indeed, in our modified IRI/FU schedule the theoretical weekly dose intensities of IRI and FU at the highest dose levels are 90 and $1660 \mathrm{mg} / \mathrm{m}^{2}$, respectively, very similar to the dose intensities of IRI and FU in the FOLFIRI and IFL regimens (Saltz et al, 2000; Douillard et al, 2000). Thus, taking into account that the rate of treatment delays or dose reductions reported in our study is low, it is reasonable to speculate that, at least at the highest dose levels, IRI and FU are not under-dosed.

Our regimen, tested as first-line treatment in 25 patients with advanced CRC, obtained a response rate $>50 \%$, a disease control rate of $80 \%$ and a time to progression of 7 months. These results are promising even though they were achieved in a dose-escalating phase I trial whose major aim was not to evaluate the antitumour activity. Taking into account that at the first dose level, we did not observe any response, probably because IRI was under-dosed, these findings are even more significant. Indeed, if only patients enrolled between the second and fifth dose levels are considered, the overall response and disease control rates reached 61.9 and $85.7 \%$, respectively. Similar results were recently achieved in a phase I dose-escalating trial of IRI and c.i. FU as first-line treatment of metastatic colorectal cancer. Interestingly, the combination was well tolerated and demonstrated a significant clinical activity, obtaining an overall response rate of $55 \%$, a clinical response benefit of $82 \%$ and a time to progression of 8 months (Saunders et al, 2004). Thus, the results of our study clearly suggest that the schedule of administration of the two drugs is critical to achieve the maximal supra-additive cytotoxic activity and that the lack of full synergism in some traditional schedules of IRI and FU may depend on the use of bolus FU (i.e. IFL) (Saltz et al, 2000) and/or the need to optimise the sequence of administration of the two agents (i.e. FOLFIRI) (Douillard et al, 2000).

Several options have been proposed to improve the efficacy of standard two-drug regimens for advanced CRC (Venook, 2005). Some studies have evaluated the combination of IRI, l-OHP and FU concurrently in a single regimen, the rationale being that nonspecific resistance to therapy may develop after first-line therapy. Indeed, these studies demonstrated that three-drug regimens achieve very high response rates $(50-70 \%)$, but also DLTs such as neutropoenia and diarrhoea (Souglakos et al, 2002; Goetz et al, 2003). Other studies have evaluated the combination of FU with l-OHP and/or IRI administered as chronomodulated infusion. These trials also reported interesting response rates and 
optimal toxicity profiles, but raised questions about the feasibility of chronomodulated chemotherapy (Garufi et al, 2003). However, the analysis of seven phase III trials in advanced CRC suggested that exposure to all three drugs, regardless of their sequence, is a key element able to extend the overall survival of patients to 18-21 months (Grothey et al, 2004). Such a prospect strongly reinforces the need to optimise doses and schedules of doublet chemotherapy, in order to deliver the three drugs sequentially and obtain maximal cytotoxic activity and minimal toxicity. Moreover, these efforts seem even more relevant in the light of the introduction in the clinical management of advanced CRC of new moleculartargeted agents with a cytostatic mechanism of action requiring precise timing when combined with traditional chemotherapeutic drugs to maximise their efficacy (Venook, 2005). The combination of IRI and cetuximab represents a salvage chemotherapy in IRIresistant patients (Venook, 2005), while the inclusion of bevacizumab in IRI/FU combination has increased both response rates and overall survival (Kelly and Goldberg, 2005). Optimising the efficacy of a combination of IRI and FU could help to enhance the overall efficacy of chemotherapy in CRC as first- or second-line therapy. Thus, this modified IRI/FU regimen may represent a precious alternative schedule with very low toxicity profile, promising clinical activity and, therefore, worth being tested in a larger phase II trial.

\section{REFERENCES}

Andre T, Louvet C, Maindrault-Goebel F, Couteau C, Mabro M, Lotz JP, Gilles-Amar V, Krulik M, Carola E, Izrael V, de Gramont A (1999) CPT11 (irinotecan) addition to bimonthly, high-dose leucovorin and bolus and continuous-infusion 5-fluorouracil (FOLFIRI) for pretreated metastatic colorectal cancer. GERCOR. Eur J Cancer 35: 1343-1347

Atalay G, Cardoso F, Paesmans M, Goldberg RM, Bleiberg H (2003) Secondline treatment in advanced colon cancer: are multiple phase II trials informative enough to guide clinical practice? Anticancer Drugs 14: $703-713$

Chou TC, Motzer RJ, Tong V, Bosl GJ (1994) Computerized quantitation of synergism and antagonism of taxol, topotecan, and cisplatin against human teratocarcinoma cell growth: a rationale approach to clinical protocol design. J Natl Cancer Inst 86: 1517-1524

Chou TC, Talalay P (1984) Quantitative analysis of dose-effect relationship: the combined effects of multiple drugs or enzyme inhibitors. $A d v$ Enzyme Regul 22: 27-55

Douillard JY, Cunningham D, Roth AD, Navarro M, James RD, Karasek P, Jandik P, Iveson T, Carmichael J, Alakl M, Gruia G, Awad L, Rougier P (2000) Irinotecan combined with fluorouracil compared with fluorouracil alone as first-line treatment for metastatic colorectal cancer: a multicentre randomized trial. Lancet 355: 1041-1047

Garufi C, Bria E, Vanni B, Zappala AM, Sperduti I, Terzoli E (2003) A phase II study of irinotecan plus chronomodulated oxaliplatin, 5-fluorouracil and folinic acid in advanced colorectal cancer patients. $\mathrm{Br} J$ Cancer 89: $1870-1875$

Goetz MP, Erlichman C, Windebank AJ, Reid JM, Sloan JA, Atherton P, Adjei AA, Rubin J, Pitot H, Galanis E, Ames MM, Goldberg RM (2003) Phase I and pharmacokinetic study of two different schedules of oxaliplatin, irinotecan, fluorouracil, and leucovorin in patients with solid tumors. J Clin Oncol 21: $3761-3769$

Grothey A, Sargent D, Goldberg RM, Schmoll HJ (2004) Survival of patients with advanced colorectal cancer improves with the availability of fluorouracil-leucovorin, irinotecan, and oxaliplatin in the course of treatment. J Clin Oncol 22: 1209-1214

Guichard S, Cussac D, Hennebelle I, Bugat R, Canal P (1997) Sequencedependent activity of the irinotecan-5FU combination in human coloncancer model HT-29 in vitro and in vivo. Int J Cancer 73: 729-734

Guichard S, Hennebelle I, Bugat R, Canal P (1998) Cellular interaction of 5-fluorouracil and the camptothecin analogue CPT-11 (irinotecan) in human colorectal carcinoma cell line. Biochem Pharmacol 55: $667-676$

Kelly H, Goldberg RM (2005) Systemic therapy for metastatic colorectal cancer: current options, current evidence. J Clin Oncol 23: 4553-4560

Khatib AM, Siegfried G, Prat A, Luis J, Chretien M, Metrakos P, Seidah NG (2001) Inhibition of proprotein convertases is associated with loss of growth and tumorigenicity of HT-29 human colon carcinoma cells: importance of insulin-like growth factor-1 (IGF-1) receptor processing in IGF-1-mediated functions. J Biol Chem 276: 30686-30693

Köhne CH, van Cutsem E, Wils J Bokemeyer C, El-Serafi M, Lutz MP, Lorenz M, Reichardt P, Ruckle-Lanz H, Frickhofen N, Fuchs R, Mergenthaler HG, Langenbuch T, Vanhoefer U, Rougier P, Voigtmann R, Muller L, Genicot B, Anak O, Nordlinger B, European Organisation for Research and Treatment of Cancer Gastrointestinal Group (2005) Phase III study of weekly high-dose infusional fluorouracil plus folinic acid with or without irinotecan in patients with metastatic colorectal cancer: European Organisation for Research and Treatment of Cancer Gastrointestinal Group Study 40986. J Clin Oncol 23: $4856-4865$

Landriscina M, Prudovsky I, Mouta Carriera C, Soldi R, Tarantini F, Maciag $\mathrm{T}$ (2000) Amlexanox reversibly inhibits cell migration and proliferation and induces the Src-dependent disassembly of actin stress fiber in vitro. J Biol Chem 275: $32753-32762$

Lesuffleur T, Kornowski A, Luccioni C, Muleris M, Barbat A, Beaumatin J, Dussaulx E, Dutrillaux B, Zweibaum A (1991) Adaptation to 5fluorouracil of the heterogeneous human colon tumor cell line HT-29 results in the selection of cells committed to differentiation. Int J Cancer 49: $721-730$

Mans DRA, Grivicich I, Peters GJ, Schwartsmann G (1999) Sequencedependent growth inhibition and DNA damage formation by the irinotecan-5-fluorouracil combination in human colon carcinoma cell lines. Eur J Cancer 13: $1851-1861$

McDonald AC, Brown R (1998) Induction of p53-dependent and p53-independent cellular responses by topoisomerase 1 inhibitors. $\mathrm{Br} \mathrm{J}$ Cancer 78: $745-751$

Mullany S, Svingen PA, Kaufmann SH, Erlichman C (1998) Effect of adding the topoisomerase I poison 7-ethyl-10-hydroxycamptothecin (SN-38) to 5-fluorouracil and folinic acid in HCT-8 cells: elevated dTTP pools and enhanced cytotoxicity. Cancer Chemother Pharmacol 42: $391-399$

O’Neil BH, Goldberg RM (2005) Chemotherapy for advanced colorectal cancer: let's not forget how we got here (until we really can). Semin Oncol 32: $35-42$

Poplin EA, Benedetti JK, Estes NC, Haller DG, Mayer RJ, Goldberg RM, Weiss GR, Rivkin SE, Macdonald JS (2005) Phase III Southwest Oncology Group 9415/Intergroup 0153 randomized trial of fluorouracil, leucovorin, and levamisole $v s$ fluorouracil continuous infusion and levamisole for adjuvant treatment of stage III and high-risk stage II colon cancer. J Clin Oncol 23: $1819-1825$

Robert J, Rivory L (1998) Pharmacology of irinotecan. Drugs Today 34(9): $777-803$

Saltz LB, Cox JV, Blanke C, Rosen LS, Fehrenbacher L, Moore MJ, Maroun JA, Ackland SP, Locker PK, Pirotta N, Elfring GL, Miller LL (2000) Irinotecan plus fluorouracil and leucovorin for metastatic colorectal cancer. $N$ Engl J Med 343: 905 - 914

Saunders MP, Hogg M, Carrington B, Sjursen AM, Allen J, Beech J, Swindell R, Valle JW (2004) Phase I dose-escalating trial of irinotecan with continuous infusion 5-FU first line, in metastatic colorectal cancer. $\mathrm{Br} \mathrm{J}$ Cancer 91: $1447-1452$

Sciamanna I, Landriscina M, Pittoggi C, Quirino M, Mearelli C, Beraldi R, Mattei E, Serafino A, Cassano A, Sinibaldi-Vallebona P, Garaci E, Barone C, Spadafora C (2005) Inhibition of endogenous reverse transcriptase antagonizes human tumor growth. Oncogene 24: 3923-3931

Souglakos J, Mavroudis D, Kakolyris S, Kourousis CH, Vardakis N, Androulakis N, Agelaki S, Kalbakis K, Tsetis D, Athanasiadis N, Samonis G, Georgoulias V (2002) Triplet combination with irinotecan plus oxaliplatin plus continuous-infusion fluorouracil and leucovorin as firstline treatment in metastatic colorectal cancer: a multicenter phase II trial. J Clin Oncol 20: $2651-2657$

Therasse P, Arbuck SG, Eisenhauer E, Wanders J, Kaplan RS, Rubinstein L, Verweij J, Van Glabbeke M, van Oosterom AT, Christian MC, Gwyther SG (2000) New guidelines to evaluate the response to treatment in solid tumours. J Natl Cancer Inst 92: 205-216 
Tournigand C, Andre T, Achille E, Lledo G, Flesh M, Mery-Mignard D, Quinaux E, Couteau C, Buyse M, Ganem G, Landi B, Colin P, Louvet C, de Gramont A (2004) FOLFIRI followed by FOLFOX6 or the reverse sequence in advanced colorectal cancer: a randomized GERCOR study. J Clin Oncol 22: 229-237

Van Triest B, Pinedo HM, van Hensbergen Y, Smid K, Telleman F, Schoenmakers PS, van der Wilt CL, van Laar JA, Noordhuis P, Jansen G, Peters GJ (1999) Thymidylate synthase level as the main predictive parameter for sensitivity to 5-fluorouracil, but not for folate-based thymidylate synthase inhibitors, in 13 nonselected colon cancer cell lines. Clin Cancer Res 5: 643-654

Venook A (2005) Critical evaluation of current treatments in metastatic colorectal cancer. The Oncol 10: 250-261
Wong NA, Brett L, Stewart M, Leitch A, Longley DB, Dunlop MG, Johnston PG, Lessells AM, Jodrell DI (2001) Nuclear thymidylate synthase expression, p53 expression and 5FU response in colorectal carcinoma. Br J Cancer 85: 1937-1943

Yoshikawa R, Kusunoki M, Yanagi H, Noda M, Furuyama JI, Yamamura T, Hashimoto-Tamaoki T (2001) Dual antitumor effects of 5-fluorouracil on the cell cycle in colorectal carcinoma cells: a novel target mechanism concept for pharmacokinetic modulating chemotherapy. Cancer Res 61: $1029-1037$

Zeghari-Squalli N, Raymond E, Cvitkovic E, Goldwasser F (1999) Cellular pharmacology of the combination of the DNA topoisomerase I inhibitor SN-38 and the diaminocyclohexane platinum derivative oxaliplatin. Clin Cancer Res 5: 1189-1196 